\title{
Urban form in special geographical conditions: A case study in Kenting National Park
}

\author{
Chih-Hung Chen, Chun-Ya Chuang 1 \\ Department of Urban Planning, National Cheng Kung University, Tainan City, Taiwan \\ E-mail: chihhungchen@mail.ncku.edu.tw ${ }^{1}$
}

\begin{abstract}
Since the land surface is heterogeneous, the natural landscape as an essential element in contemporary morphological studies becomes the initial factor in the formation of a settlement. Moreover, the interaction with natural landscape, built form and the boundary matrix can illuminate ecological perspective on the form of the city (Scheer, 2016). To understand the urban form under special geographical conditions, a case study is conducted in Kenting National Park, which is a tropical area with rich landscape such as mountains, lakes and rivers, plains, basins, and surrounded by seas. An analytical approach based on Historico-Geographical approach (Kropf, 2009; Oliveira, 2016) is applied in this paper. Three kinds of plan units (Conzen, 1960) by comparing the combination between streets, buildings and plots: i) Detached, duplex houses on small plots along the access road; ii) Attached buildings on small plots along the main road; iii) Public buildings, Villas, and hotels on large plots along the main road. Finally, the relationship between the morphotopes (Conzen, 1988) and the geographical conditions shows that the homogeneous configuration of plan units corresponds to the certain landscape. On the other hand, this article finds out that the site may directly affect the size and accessibility of settlements. In other words, the special geographical conditions not only determine the formation of urban form but a certain degree of socio-economic context.
\end{abstract}

Keywords: Kenting National Park, special geographical conditions, Historico-Geographical approach, morphotope.

\section{Introduction}

In many geography theories considers landscape is homogeneous, such as central place theory, the real world's surface is heterogeneous. In response to the neglect of natural landscapes, Michael Hough criticizes urban design without regard to the natural environment. The neglect leads the city to replace mixed forest communities, fields and rivers, destroying the original self-sustaining ecosystem. Therefore, Michael Hough said that urban design must bases on an environmental perspective (Hough, 2004). Also, with the trend of sustainable development, natural landscape has become one of the important factors in contemporary morphological studies. The interaction with natural landscape, built form and the boundary matrix can illuminate ecological perspective on the form of the city (Scheer, 2016). In order to explore the interaction between urban and natural environment, this paper chooses three settlements in Taiwan's Kenting National Park as a case study.

Taiwan Island is shaped by plate movement and has the highest peak in East Asia and complex landscape. Among them, Hengchun Peninsula, the southern part of Taiwan Island, is a collection of diverse landscape. It is at 
the end of the Central Range and adjacent to the Taiwan Strait, the Bashi Channel, and the Pacific Ocean. Hengchun Peninsula has a unique coral reef geology, rich tropical and marine ecological landscape (figure1). The rich geographical condition, however, became natural barriers that limited the settlement development and resulted in the unique development processes to respond to the natural environment. In 1982, Kenting designated as the first national park in Taiwan. Under the protection of the National Park Law, Lots of settlements in was saved. It is the relatively isolated feature makes Kenting a suitable case to find out the impacts and changes caused by special geographical conditions.

\section{Method}

According to Kropf (2009), urban form consists of site, social and economic context, function, land utilization, townscape, and development. Among them, the site mainly based on geological, topography, hydrology and other natural physical characteristics of the spatial relationship and distribution. It is of particularly importance under the special geographical conditions of Kenting National Park.

The historico-geographical approach (Town plan analysis) is applied to describe and analyze the physical form and the evolution of settlements in Kenting National Park (Kropf, 2009). Due to the natural landscape constraints, the scale of the settlements in Kenting National Park is small. That's the reason why this paper use morphotope as the basic unit for observing the morphological region. The analysis is first focus on the utilization of buildings, then figure out the plan units of residential or commercial buildings and public use buildings.

With the absence of historical town plans, morphological analysis at a micro scale can be an alternative means of investigation (Chakma et al., 2013). Therefore, the case study is conducted in Syunguangzui, Kenting, and Yongjing. The primary data source is

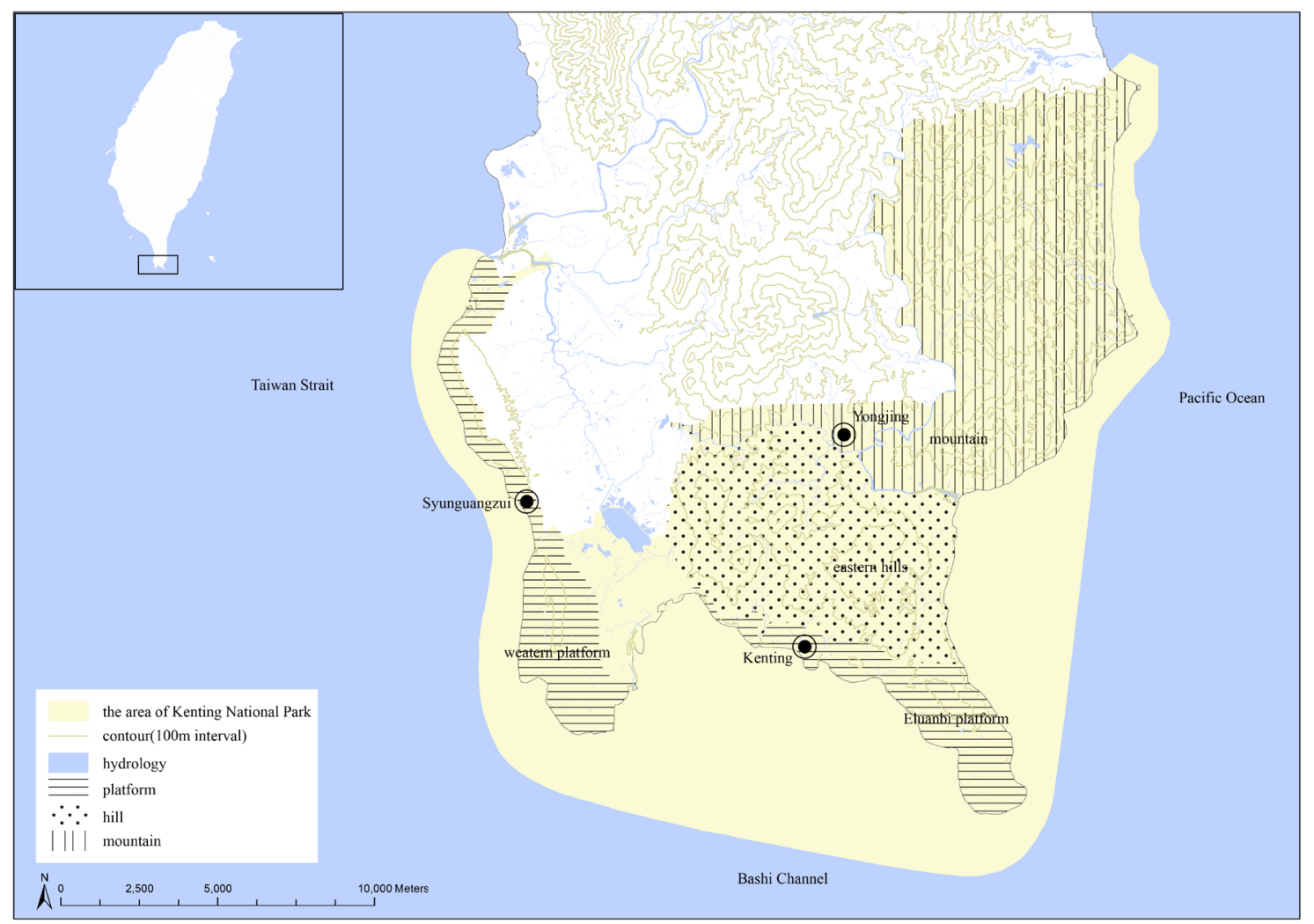

Figure 1. Geographical situation of Kenting National Park (source: National Land Surveying and Mapping Center, Ministry of the Interior, 2012) 
Taiwan Electronic Map. For the 1: 5000-scale digital topographic maps, the map information contains roads, water, administrative, building and so on.

\section{Kenting: a mixture of natural wonders}

Kenting National Park is located in the southern part of Taiwan Island; the terrain is high in the East and low in the West. Uplifted coral outcroppings, limestone caves, and isolated peaks are dominant geologic features of Kenting. The terrain in the area can be divided into three part, including the western platform, the Eluanbi platform and the eastern hills and mountains (Figure 1).

The area of Kenting National Park is lack of water resources due to the coral reef geology cannot keep water. Moreover, the river is steep and the rainfall flows directly into the sea. As a result, the distribution of settlements is often related to water resources.

As Kenting National Park is located in the monsoon region, the area in the northeastern monsoon windward surface is the subtropical regional characteristics; leeward side is a tropical area. The northeastern monsoon prevailing from October to March of each year will produce "foehn" over the mountains. Interestingly, the impact of foehn is also reflected in the physical form. In the past, most of the buildings are thatched cottages. To avoid the roof blew off by the foehn, residents put stones on the roof of thatch cottages. Even if the brick building structure is stronger, it still needs to strengthen the roof reinforcement measures. As reinforced concrete structures with better resistance to the wind, reinforced concrete buildings are becoming more and more popular. Thus accelerate the speed of replacement of traditional buildings.

\section{The historical context of Kenting}

Before the middle of the seventeenth century, the principal activities of Aborigines were

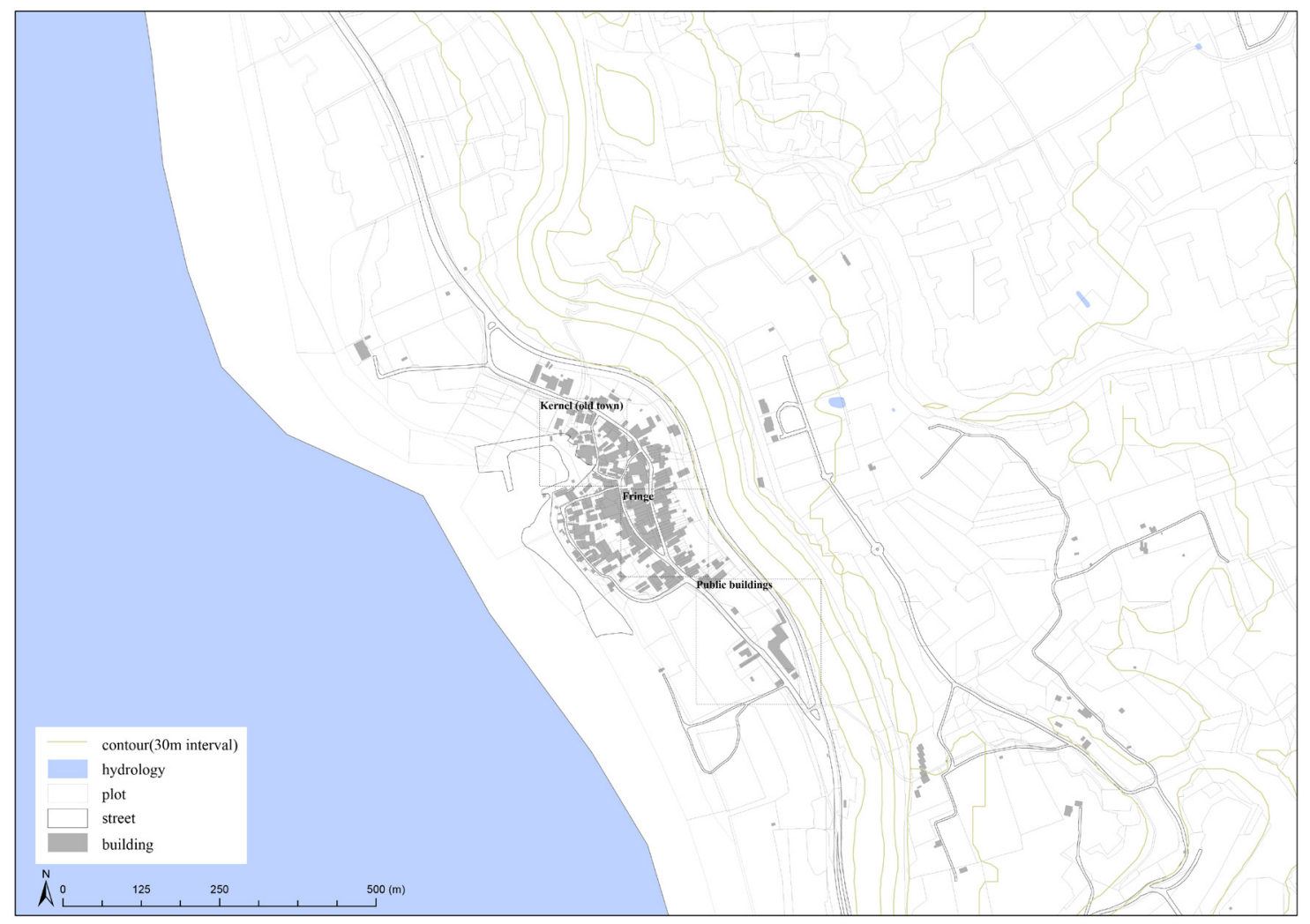

Figure 2. Plan of Syunguangzui in western platform area(source: National Land Surveying and Mapping Center, Ministry of the Interior, 2012) 
in the eastern hills and mountains area. The settlement of the Han people can be traced back to 1661 , reclamation from the western platform, plain area, and gradually eastward development.

However, under the constraints of terrain, the impact of traffic on the development of settlements is the most significant, whether it is indigenous tribe or Han Chinese settlement.

\section{Synchronic comparison between Syunguangzui, Kenting, and Yongjing}

Syunguangzui, Kenting, and Yongjing are the larger settlements in the three special terrain areas of the Kenting National Park. Although they are located in different natural landscapes, they have similar morphotopes. The following will be a brief description of the site, social and economic context, and the spatial structure of the three settlements.

\section{Syunguangzui}

Syunguangzui is located in a natural harbor beneath the western platform. The east side of the settlement is close to a cliff, the west side is close to the Taiwan Strait. The buildings are concentrated on both sides of the access road connecting the main road (Figure 2).

Shanhai Fishery Harbor is the oldest fishing port in Hengchun Peninsula. Since the sea is the most important local traffic before the land transport opened, there was a way build in 1984 to link Hengchun City and the harbor (Chen and Tu, 1983). The junction of the road and the port was the core of the settlement, and now can still see the layout of detached houses scattered. In the past, the fishery was the primary industry. In recent years, since the flourish of sightseeing activities, residents were engaged in Snorkeling, bed and breakfast and other related activities.

There are three main types of plan units in Syunguangzui (Figure 5). First of all, the core area, which is also the center of religion, close

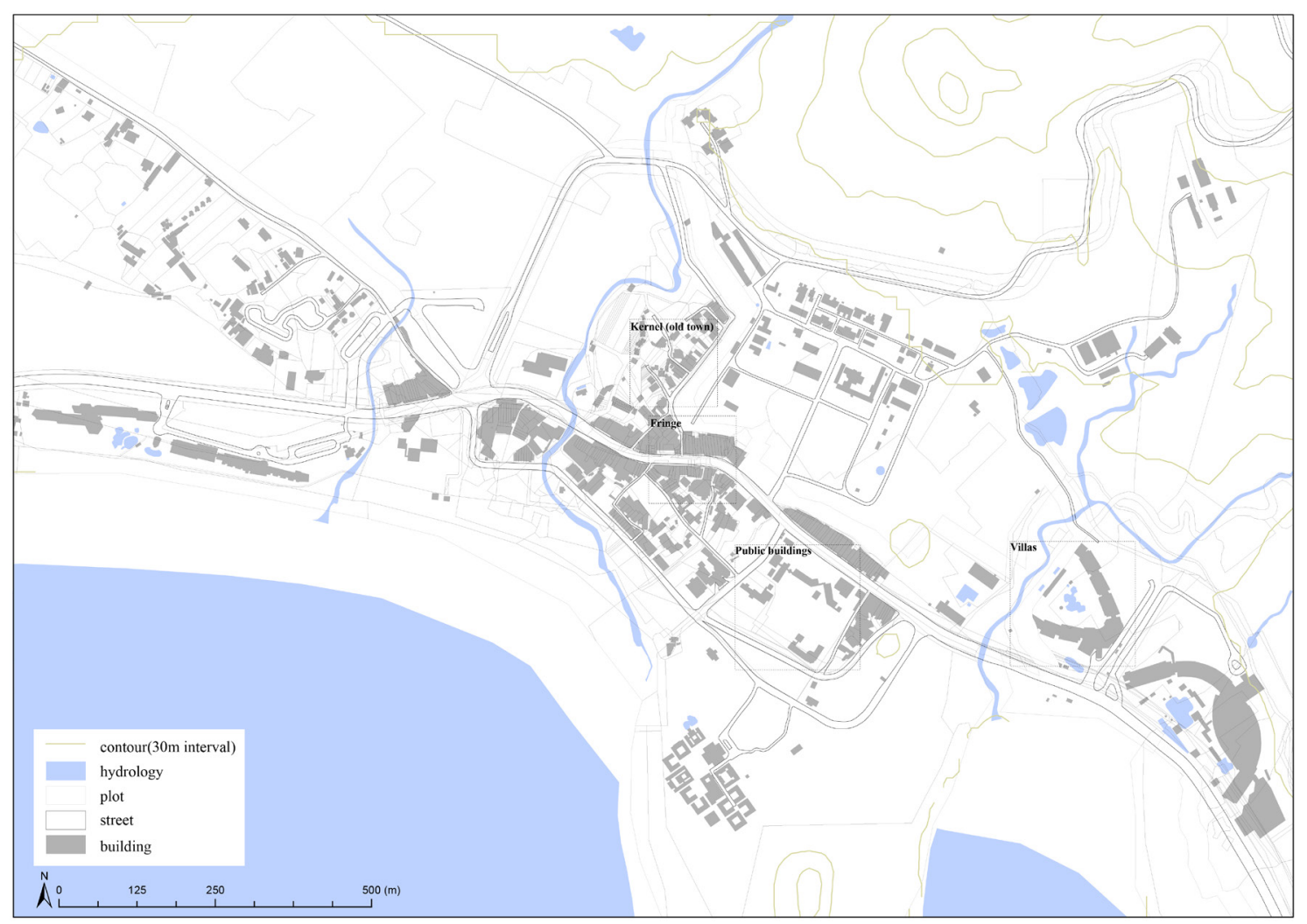

Figure 3. Plan of Kenting in Eluanbi platform area(source: National Land Surveying and Mapping Center, Ministry of the Interior, 2012) 
to the Shanhai Fishery Harbor. The plan unit is mostly detached, duplex houses on small plots along the access road. Second, the fringe of the settlement, which is on the southeast side of the core, develops along the main road. The plan unit is attached buildings for residential use on small plots along the main road. Besides, there is an elementary school outside the settlement. As the need for a larger plot, the public building distributed on the edge of the settlement. Because of the terrain barrier, the settlements are far apart, therefore schools are small but densely distributed.

\section{Kenting}

Kenting is located in the area of Eluanbi platform. The coastline segment of Kenting National Park offers the finest water-based recreation in Taiwan. The coral reefs, protected beaches and blue waters between Maopitou and Oluanpi allow for swimming, sailing, sport finishing, sunbathing, snorkeling and scuba diving. As the terrain of Kenting has relatively flat, larger hinterland, and close to the main road, it is the largest settlement among the three settlements chosen as the case (Figure 3 ).

Reclamation in the region dates back to 1877. In 1895, after Taiwan ceded to Japan, Japan brought new local economic sources. In 1905, because the foehn help clear the bacteria, the Japanese government set up "Kenting Ranch" in Kenting. Establishing the dependence between Kenting Ranch and Kenting people for more than 100 years. In 1986, Kenting was reported as the best place to watch Halley comet in Taiwan. Since then, the Kenting beach area has started to change from Primary industrial sectors to Tertiary industrial sectors. This attracts the emergence of bed and breakfast and the the hotel.

There are four kinds of plan units in Kenting (Figure 5). First, the old town on the west side of the ranch is the earliest development of the location of Kenting. The combination between streets, buildings and plots is detached, duplex houses on small plots along the access

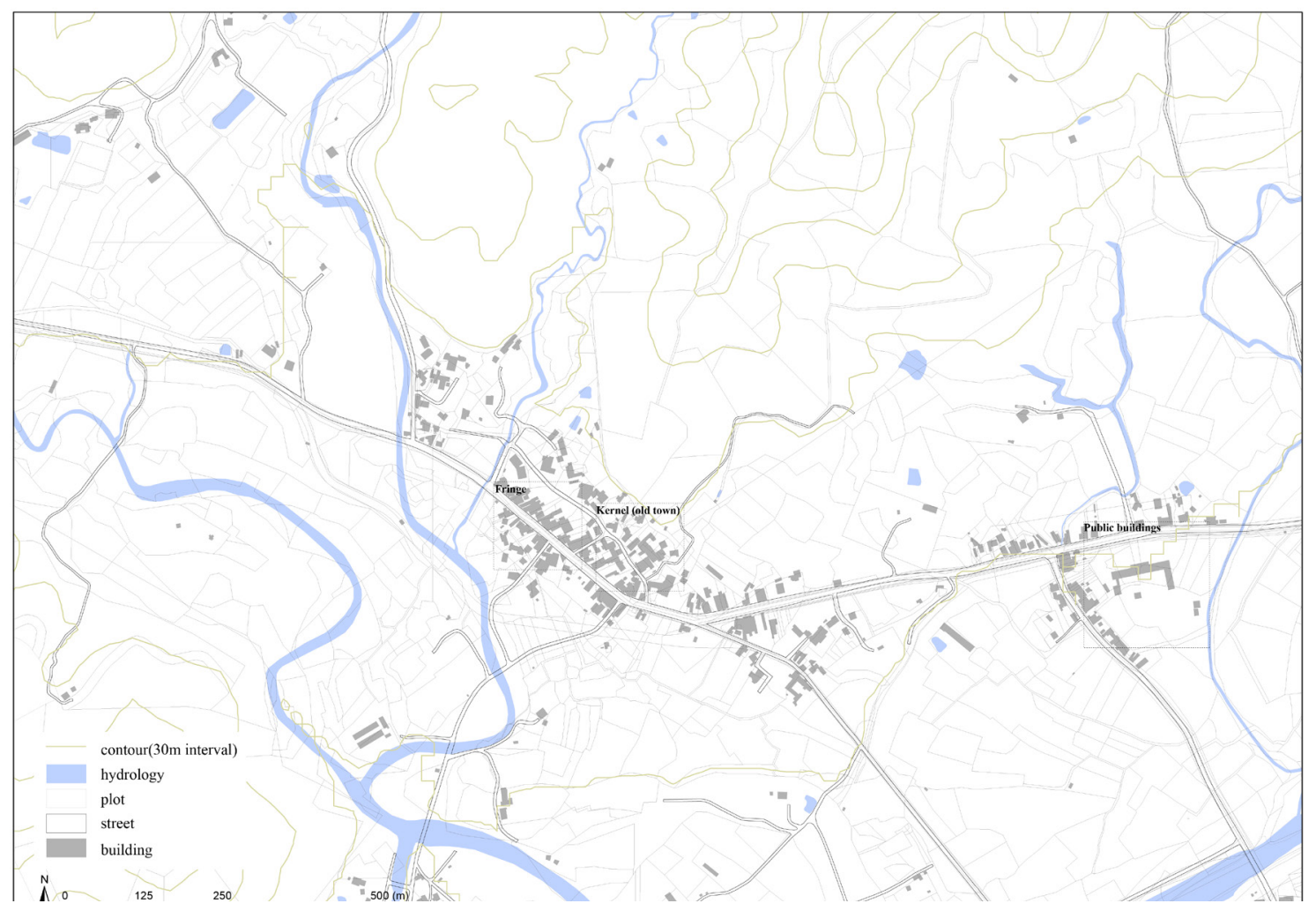

Figure 4. Plan of Yongjing in eastern hills and mountain area(source: National Land Surveying and Mapping Center, Ministry of the Interio ${ }^{r}$, 2012). 
road. However, due to the rise of the tourism industry, the area near the main road appears replacement for attached buildings to replace detached, duplex houses. The second plan unit is the attached buildings for commercial use on small plots along the main road. The place is also the current development focus area. Third, there is an elementary school on the edge of the settlement, because the site of the settlement can provide enough land. Finally, due to the development of the tourism industry, the outermost side of the Kenting settlement is made up of large hotels that have developed along the main road.

\section{Yongjing}

Yongjing is located in the eastern hills and mountains area of Kenting National Park. Yongjing east facing the Pacific Ocean, north side close to the mountains, south of the river flow (Figure 4). Residents are dominated by aborigines, and agriculture is the main industry.

Yongjing's plan units can be divided into three kinds (Figure 5). First, the eastern side of the settlement is the development of the core area. The combination between streets, buildings and plots is detached, duplex houses for residential use on small plots along the access road. Second, along the main road to the development of the fringe. The plan unit

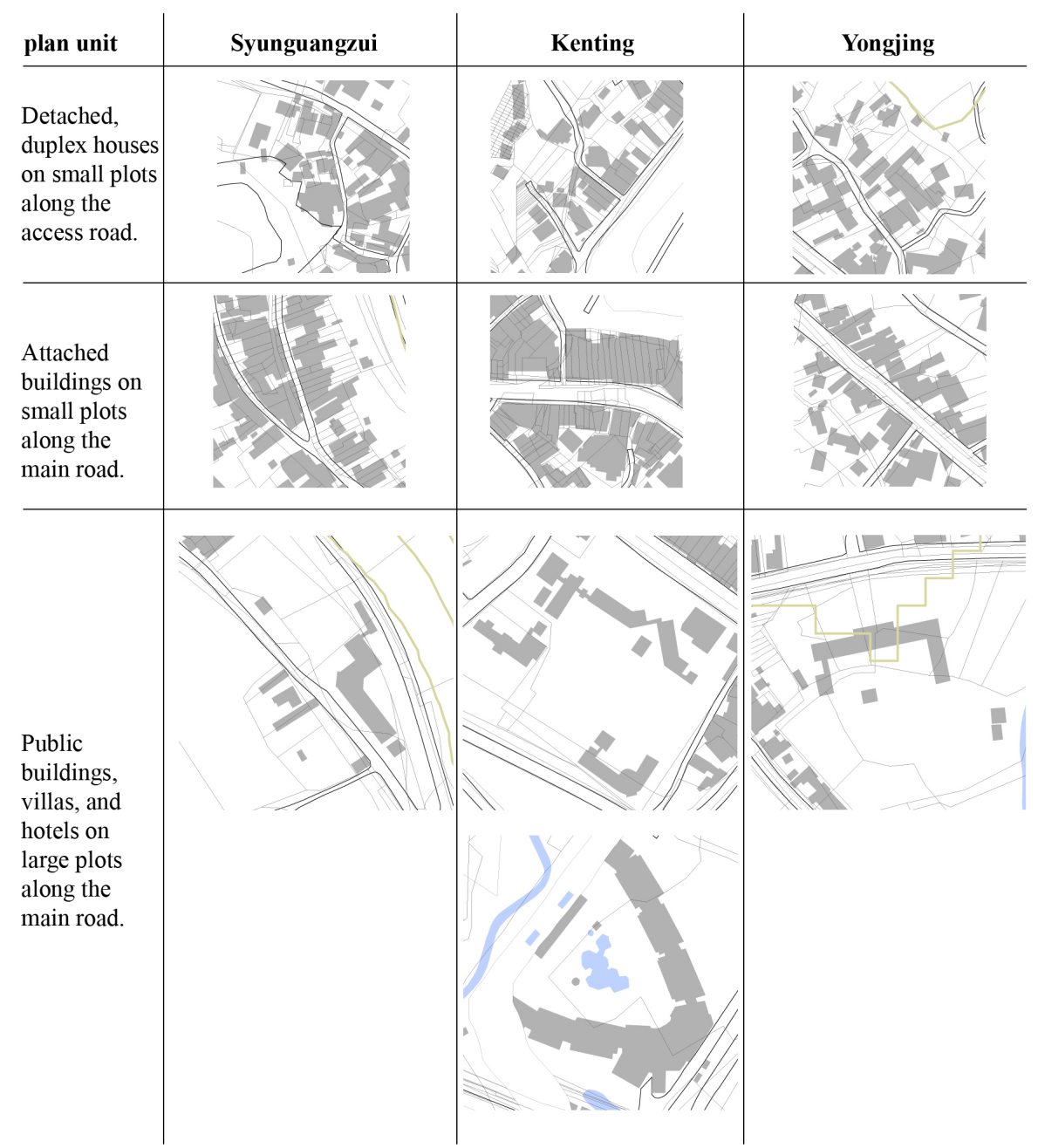

Figure 5. The plan units of Syunguangzui, Kenting and Yongjing 
is mostly attached buildings on small plots along the main road. Finally, the distribution of public building is on the eastern side of the other settlement with an elementary school.

\section{Conclusion}

In summary, the three settlements in common are all limited by terrain. According to the hinterland size is followed by Kenting, Yongjing and Syunguangzui. Thus we can see the site may affect the size of the settlement. Compare with the accessibility, only Kenting links to the main road where you can contact other counties. As a result, the site affects the size and accessibility of these settlements, and these differences would make a difference in the development process. In other words, the closer to the main road of the settlement, the higher possibility of change. For example, Kenting in the past to agriculture for a living, now Kenting Street has become the main purpose for tourists who come to Kenting National Park.

Also, the settlement is limited by the size of the settlement and the development of hinterland, to obtain enough building base to build large facilities, public facilities are mostly located on the edge of the settlement, the distribution of large hotels show the similar way in site choice.

\section{References}

Chakma, M., Guaralda, M., \& Sanders, P. S. (2016) Dwellings in the borderland: A study of traditional hill settlements in the Chittagong Hill Tracts of Bangladesh. Urban Form at the Edge: Proceedings from ISUF 2013: Volume 2, 2, 19-37.

Chen, W. \& Tu, J. (1983) Hengchun County. (Cheng wen chu ban she, Taipei).

Conzen, M. R. G. (1960) Alnwick, Northumberland: A study in Town-plan Analysis (Institute of British Geographers, London).

Conzen, M.R.G. (1988) 'Morphogenesis, morphological regions, and secular human agency in the historic townscape, as exemplified by Ludlow', in Denecke, D. and Shaw, G. (ed) Urban Historical Geography. Recent progress in Britain and Germany, 253-272.

Hough, M. (2004) Cities and natural process. Routledge.

Kropf, K. (2009) 'Aspects of urban form', Urban morphology 13(2), 105-20.

National Land Surveying and Mapping Center, Ministry of the Interior (cartographer) (2012) Taiwan Electronic Map [map] 1:5,000(National Land Surveying and Mapping Center, Ministry of the Interior, Taiwan)

Oliveira, V. (2016) Urban Morphology (Springer International Publishing, Switzerland), 102-111.

Scheer, B. C. (2016) 'The epistemology of urban morphology', Urban Morphology 20, 5-17. 